\title{
Clinicopathological analysis of salivary gland tumors over a 15-year period
}

\section{Artur Cunha VASCONCELOS(a) Felipe NÖR(a) \\ Luise MEURER ${ }^{(b)}$ \\ Gabriela SALVADORI(c) \\ Lélia Batista de SOUZA ${ }^{(\mathrm{d})}$ \\ Pablo Agustin VARGAS $(\mathrm{e})$ \\ Manoela Domingues MARTINS ${ }^{(a)}$}

(a) Universidade Federal do Rio Grande do Sul - UFRGS, School of Dentistry, Department of Oral Pathology, Porto Alegre, RS, Brazil.

(b) Universidade Federal do Rio Grande do Sul - UFRGS, Hospital de Clínicas de Porto Alegre, Department of Pathology, Porto Alegre, RS, Brazil.

(c) University of Oslo - UiO, Faculty of Dentistry, Institute of Oral Biology, Oslo, Norway.

(d) Universidade Federal do Rio Grande do Norte - UFRN, Centro de Ciências da Saúde, Departamento de Odontologia, Natal, RN, Brazil.

(e) Universidade Estadual de Campinas - UNICAMP, Piracicaba Dental School, Department of Oral Diagnosis, Piracicaba, SP, Brazil.

Declaration of Interests: The authors certify that they have no commercial or associative interest that represents a conflict of interest in connection with the manuscript.

Corresponding Author:

Manoela Domingues Martins

E-mail: manomartins@gmail.com

DOI: 10.1590/1807-3107BOR-2016.vol30.0002

Submitted: Sep 24, 2014

Accepted for publication: Jun 19, 2015

Last revision: Aug 24, 2015
Abstract: Salivary gland tumors (SGT) are rare neoplasms that generate interest due to their histopathological diversity and clinical behavior. The aims of the present study were to investigate clinicopathological aspects of SGTs diagnosed at a tertiary health center and compare the findings with epidemiological data from different geographic locations. Cases of tumor in the head and neck region at a single health center in the period between 1995 and 2010 were reviewed. Patient gender, age and ethnic group as well as anatomic location, histological type and clinical behavior of the tumor were recorded. Availability of complete information about these aspects was considered the inclusion criteria. Descriptive statistical analysis of the data was performed using the frequencies of categorical variables. Among the 2168 cases of tumors in the head and neck region, $243(11.20 \%)$ cases were diagnosed in the salivary glands, 109 of which met the inclusion criteria: 85 (78\%) benign tumors and $24(22 \%)$ malignant tumors. Mean patient age was 46.47 years. The female gender accounted for 56 cases $(51.4 \%)$ and the male gender accounted for 53 (48.3\%). The major salivary glands were affected more $(75.2 \%)$ than the minor glands. The most frequent benign and malignant SGTs were pleomorphic adenoma (81.2\%) and adenoid cystic carcinoma (58.3\%), respectively. In conclusion, pleomorphic adenoma and adenoid cystic carcinoma are the most frequent benign and malignant lesions, respectively. Comparing the present data with previous studies on SGTs, one may infer that some demographic characteristics and the predominance of malignant tumors vary in different geographic regions.

Keywords: Neoplasms; Salivary Glands; Adenoma, Pleomorphic; Carcinoma, Adenoid Cystic; Carcinoma, Mucoepidermoid.

\section{Introduction}

Salivary glands tumors (SGTs) are uncommon neoplasms that pose a diagnostic challenge due to their complex histopathological features. ${ }^{1}$ Moreover, SGTs exhibit considerable variation with regard to clinical aspects, biology and clinical behavior. ${ }^{2,3,4}$

SGTs represent 3 to $6 \%$ of all tumors of the head and neck region, with an annual incidence throughout the world ranging from 0.05 to 2 cases per 100,000 individuals. ${ }^{5}$ Epidemiological data reveal different frequencies of SGTs in distinct ethic groups and geographic locations, which makes it difficult to establish global estimates. ${ }^{1,6,7,8,9,10,11,12,13,14,15,16}$ Although 
studies provide valuable knowledge, some data are contradictory. Local records are a useful strategy for the analysis of the distribution and particular features of SGTs in a specific population and the establishment of appropriate treatment.

The aims of present study were to describe demographic and clinicopathological aspects of SGTs diagnosed at a tertiary health center and compare the findings with epidemiological data from different geographic locations.

\section{Methodology}

A retrospective analysis was carried out using archival data from the pathology laboratory of a tertiary health center located in southern Brazil Hospital de Clínicas de Porto Alegre. This study received approval from the Institutional Ethics Committee (protocol no. 130152/12).

In a 15-year period spanning from 1995 to 2010, 2168 cases of tumors in the head and neck region were identified, 243 of which were SGTs. Clinical data regarding age, gender, clinical aspects, tumor localization, TNM Classification, treatment and follow-up information (clinical outcome and survival time) were retrieved from medical files. The follow-up period was defined as the time from diagnosis until the last visit to the hospital. Availability of complete information about these aspects was considered the inclusion criteria and based on these only 109 were included. Slides stained with hematoxylin-eosin of all cases were reviewed based on the Histologic Typing of Salivary Gland Tumors established by the World Health Organization (WHO). ${ }^{17}$ Continuous variables were expressed as mean, median and standard deviation values. Categorical variables were expressed as absolute number of cases and percentage values.

\section{Results}

Among the 109 cases of SGTs, 81 (74.3\%) tumors were located in major salivary glands and 28 (25.7\%) were located in minor salivary glands. The most frequent location among the major salivary glands was the parotid gland (66.9\%), followed by the submandibular gland (7.3\%). Among the minor glands, the most frequent location was the palate
(14.6\%). No cases occurred in the sublingual gland (Figure and Table 1).

The male gender accounted for 53 cases (48.3\%) and the female gender accounted for 56 (51.4\%): male-to-female ratio of 0.9:1 for benign tumors and 1:1 for malignant tumors (Table 2). The majority of the tumors occurred in patients aged 41 to 60 years (median: 45 years). Mean patient age was 46.47 years (47.6 years for benign tumors and 42.3 years for malignant tumors). Young individuals ( $0-20$ years-old) were the second group more affected by malignant tumors (25\%) (Table 3).

Eighty-five cases (78\%) were classified as benign tumors and $24(22 \%)$ were malignant tumors (benign-to-malignant ratio of 3.5:1). The proportions differed depending on the type of salivary gland analyzed. Among the 81 cases of SGT in the major glands, 67 (82.7\%) were benign and 14 (17.3\%) were malignant. Among the 28 cases in minor salivary glands, 18 (64.3\%) were benign and 10 (35.7\%) were malignant (Table 1). Among the 85 benign tumors, 68 (79.06\%) were pleomorphic adenoma and 16 (18.6\%) were cases of Warthin's tumor. Among the 24 malignant tumors, 14 (58.3\%) were adenoid cystic carcinoma, five (20.8\%) were mucoepidermoid carcinoma and five (20.8\%) were acinic cell carcinoma (Table 1).

Adenoid cystic carcinoma and mucoepidermoid carcinoma were classified based on the WHO Histologic Typing of Salivary Gland Tumors. ${ }^{17}$ Among the 14 cases of adenoid cystic carcinoma,

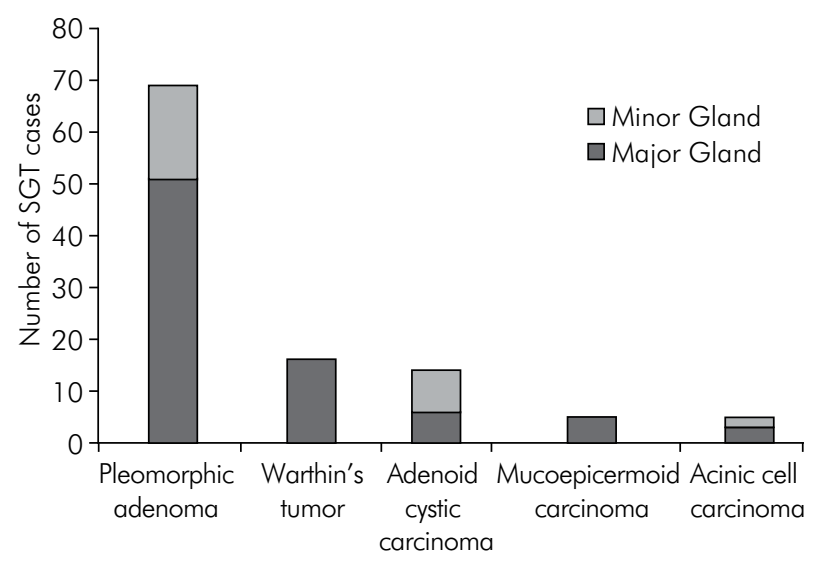

Figure. Distribution of 109 salivary gland tumors according to occurrence in major or minor salivary glands. 
Table 1. Distribution of 109 salivary gland tumors according to anatomic location.

\begin{tabular}{|c|c|c|c|c|c|c|c|c|}
\hline & \multicolumn{2}{|c|}{ Parotid } & \multicolumn{2}{|c|}{ Submandibular } & \multicolumn{2}{|c|}{ Palate } & \multicolumn{2}{|c|}{ Other } \\
\hline & $\mathrm{n}$ & $\%$ & $\mathrm{n}$ & $\%$ & $\mathrm{n}$ & $\%$ & $\mathrm{n}$ & $\%$ \\
\hline \multicolumn{9}{|l|}{ Benign tumors } \\
\hline Pleomorphic adenoma & 48 & 69.6 & 3 & 4.3 & 11 & 15.9 & 7 & 10.1 \\
\hline Warthin's tumor & 16 & 100.0 & 0 & 0.0 & 0 & 0.0 & 0 & 0.0 \\
\hline Subtotal (\% in the group of benign tumors) & 64 & 75.3 & 3 & 3.5 & 11 & 12.9 & 7 & 8.2 \\
\hline \multicolumn{9}{|l|}{ Malignant tumors } \\
\hline Adenoid cystic carcinoma & 3 & 21.4 & 3 & 21.4 & 4 & 28.6 & 4 & 28.6 \\
\hline Mucoepidermoid carcinoma & 3 & 60.0 & 2 & 40.0 & 0 & 0.0 & 0 & 0.0 \\
\hline Acinic cell carcinoma & 3 & 60.0 & 0 & 0.0 & 1 & 20.0 & 1 & 20.0 \\
\hline Subtotal (\% in the group of malignant tumors) & 9 & 37.5 & 5 & 20.8 & 5 & 20.8 & 5 & 20.8 \\
\hline Total $(\%$ according $n=109)$ & 73 & 66.9 & 8 & 7.3 & 16 & 14.7 & 12 & 11.0 \\
\hline
\end{tabular}

Table 2. Histologic and gender distribution of 109 salivary gland tumors.

\begin{tabular}{|c|c|c|c|c|c|c|c|}
\hline & \multirow{3}{*}{$\mathrm{n}=109$} & \multirow{3}{*}{$\%$} & \multirow{3}{*}{$\begin{array}{c}\% \text { in the group of benign or } \\
\text { malignant tumors }\end{array}$} & \multicolumn{4}{|c|}{ Gender } \\
\hline & & & & \multicolumn{2}{|c|}{ Male } & \multicolumn{2}{|c|}{ Female } \\
\hline & & & & $\mathrm{n}$ & $\%$ & $\mathrm{n}$ & $\%$ \\
\hline \multicolumn{8}{|l|}{ Benign tumors } \\
\hline Pleomorphic adenoma & 69 & 63.3 & 81.2 & 31 & 28.4 & 38 & 34.9 \\
\hline Warthin's tumor & 16 & 14.7 & 18.8 & 10 & 9.2 & 6 & 5.5 \\
\hline Total & 85 & 78 & 100 & 41 & 37.6 & 44 & 40.4 \\
\hline \multicolumn{8}{|l|}{ Malignant tumors } \\
\hline Adenoid cystic carcinoma & 14 & 12.8 & 58.3 & 6 & 5.5 & 8 & 7.3 \\
\hline Mucoepidermoid carcinoma & 5 & 4.6 & 20.8 & 3 & 2.7 & 2 & 1.8 \\
\hline Acinic cell carcinoma & 5 & 4.6 & 20.8 & 3 & 2.7 & 2 & 1.8 \\
\hline Total & 24 & 22 & 100 & 12 & 10.9 & 12 & 10.9 \\
\hline
\end{tabular}

Table 3. Distribution of 109 benign and malignant salivary gland tumors according to age (in years).

\begin{tabular}{|c|c|c|c|c|c|c|c|c|}
\hline & \multicolumn{2}{|c|}{$0-20$} & \multicolumn{2}{|c|}{$21-40$} & \multicolumn{2}{|c|}{$41-60$} & \multicolumn{2}{|c|}{$>61$} \\
\hline & $\mathrm{n}$ & $\%$ & $\mathrm{n}$ & $\%$ & $\mathrm{n}$ & $\%$ & $\mathrm{n}$ & $\%$ \\
\hline \multicolumn{9}{|l|}{ Benign tumors } \\
\hline Pleomorphic adenoma & 5 & 7.2 & 24 & 34.8 & 28 & 40.6 & 12 & 17.4 \\
\hline Warthin's tumor & 0 & 0.0 & 0 & 0.0 & 9 & 56.3 & 7 & 43.8 \\
\hline Subtotal (\% in the group of benign tumors) & 5 & 5.9 & 24 & 28.2 & 37 & 43.5 & 19 & 22.4 \\
\hline \multicolumn{9}{|l|}{ Malignant tumors } \\
\hline Adenoid cystic carcinoma & 1 & 7.1 & 2 & 14.3 & 8 & 57.1 & 3 & 21.4 \\
\hline Mucoepidermoid carcinoma & 2 & 40.0 & 0 & 0.0 & 2 & 40.0 & 1 & 20.0 \\
\hline Acinic cell carcinoma & 3 & 60.0 & 2 & 40.0 & 0 & 0.0 & 0 & 0.0 \\
\hline Subtotal (\% in the group of malignant tumors) & 6 & 25.0 & 4 & 16.7 & 10 & 41.7 & 4 & 16.7 \\
\hline Total $(\%$ according $n=109)$ & 11 & 10.1 & 28 & 25.7 & 47 & 43.1 & 23 & 21.1 \\
\hline
\end{tabular}


seven $(50.0 \%)$ cases were cribriform, five $(35.7 \%)$ were tubular and two (14.3\%) were solid. Among the five cases of mucoepidermoid carcinoma, four were classified as low-grade and one was classified as intermediate-grade.

Regarding the clinical aspects, all benign tumors were nodules, whereas malignant tumors were nodules in 19 cases (11 cases of adenoid cystic carcinoma, four cases of mucoepidermoid carcinoma and four cases of acinic cell carcinoma) and ulcerated nodules in five cases (three cases of adenoid cystic carcinoma, one case of mucoepidermoid carcinoma and one case of acinic cell carcinoma). Among the 24 malignant tumors, $11(45.8 \%)$ cases were classified as TNM stage I or II and 13 (54.2\%) cases were classified as stage III or IV.

All patients underwent surgical treatment. Thirteen patients (11.92\%) with malignant tumors also underwent radiation therapy. Among these patients, seven $(53.8 \%)$ cases were adenoid cystic carcinoma, three $(23.1 \%)$ were mucoepidermoid carcinoma and three (23.1\%) were acinic cell carcinoma. The follow-up period ranged from four to 17 years (mean: 7.4 years). During the follow-up period, 19 patients $(79.2 \%)$ of malignant lesions remained alive without recurrence and only one (4.2\%) remained alive but with recurrence (adenoid cystic carcinoma). One patient (4.2\%) died due to an unspecified cause and three (12.6\%) died due to the tumor (TNM stages III and IV): one case (4.2\%) of acinic cell carcinoma and two cases $(8.4 \%)$ of adenoid cystic carcinoma. Recurrence was observed in four cases $(3.66 \%)$ of pleomorphic adenoma and four cases $(3.66 \%)$ of adenoid cystic carcinoma.

\section{Discussion}

A morphologically diverse group of rare tumors arises from salivary glands. These tumors have different biological behaviors and their etiopathogenesis remains unknown. ${ }^{2,5}$ Epidemiologic studies conducted in different parts of the world report differences in the incidence as well as frequency of histological types of SGTs (Table 4). The present study reviewed the demographic and clinicopathologic aspects of 109 cases of SGTs diagnosed at a tertiary health center and the findings are in general agreement with data reported in previous studies. ${ }^{1,8,10,12,15,16,18}$
According to the literature, the most common clinical presentation of SGT is a well-circumscribed nodular tumor with a normal overlying surface color. SGTs are usually asymptomatic and affect females more, with peak incidence occurring the fifth and seventh decades of life. ${ }^{10,15,17,19,20,21,22}$ The clinical features that allow the differentiation of benign and malignant SGTs are the evolutionary course, pain and ulceration. Benign tumors tend to be insidious and slow growing, with an average course of three to six years and no adherence to surrounding tissues. Malignant lesions exhibit fast growth (often less than one year of evolution) and adhere to deep layers, with an ulcerated or telangiectatic surface. Pain is the most suggestive characteristic of malignancy. ${ }^{17}$ In the present series, the majority of clinical characteristics observed were similar to those reported in previous studies. Patient age ranged from nine to 81 years old, with a mean of 46.47 years. The tumors were all nodules and $4.6 \%$ were ulcerated. The only difference in comparison to previous reports was the similar male-to-female ratio (0.94:1) with both benign and malignant tumors. Although uncommon, Lukšić et al. ${ }^{15}$ and Tian et al. ${ }^{16}$ report similar findings.

Major salivary glands were affected more than minor glands, especially the parotid gland (66.9\%), followed by palatine glands (14.7\%). Similar results are described in the majority of studies on SGTs (Table 4), including those from Brazil (Table 5), ${ }^{1,6,7}$ The predominance of SGTs in major salivary glands may be explained by the fact that the present study was conducted at tertiary health center that receives most patients with parotid tumors. SGTs in minor salivary glands are usually diagnosed and treated at primary and secondary services, whereas only malignant SGTs in major salivary glands are referred to the hospital service.

Benign SGTs predominated in the major glands and comprised $78 \%$ of all salivary tumors, which is similar to rates reported in studies conducted in Iran, ${ }^{19}$ Congo, ${ }^{18}$ the United Kingdom, ${ }^{23}$ Jordan, ${ }^{24}$ Brazil ${ }^{6,7}$ and China, ${ }^{16}$ in which benign tumors accounted for more than $50 \%$ of all salivary tumors, suggesting that such tumors are the predominant form of SGTs worldwide. In the present study, the benign-to-malignant ratio was 3.5:1. Few studies report a greater prevalence 
Table 4. Distribution of salivary gland tumors in different countries.

\begin{tabular}{|c|c|c|c|c|c|c|c|c|c|}
\hline \multirow{2}{*}{ Region } & \multirow{2}{*}{ Authors } & \multirow{2}{*}{$\begin{array}{c}\text { Number of cases } \\
\text { (n) }\end{array}$} & Benign & Malignant & Major & Minor & PA & CAC & MEC \\
\hline & & & \multicolumn{7}{|c|}{ (\% of all tumors) } \\
\hline China & Tian et al. 2010 & 6982 & 67.9 & 32.1 & 71.6 & 28.4 & 47 & 9.7 & 9.6 \\
\hline China & Li et al. 2008 & 3461 & 59.8 & 40.2 & 73.6 & 26.4 & 51.3 & 7.3 & 7.5 \\
\hline USA & Spiro et al. 1986 & 2807 & 54.5 & 45.5 & 78 & 22 & 45.4 & 10 & 15.7 \\
\hline Finland and Israel & Bello et al. 2012 & 1888 & 85.1 & 14.9 & 90 & 10 & 50 & 3.5 & 3.2 \\
\hline Croatia & Luksic et al. 2011 & 779 & 64.2 & 35.8 & 72.8 & 27.2 & 47.2 & 11.7 & 8.2 \\
\hline UK & Jones et al. 2008 & 741 & 64.9 & 35.1 & 38.6 & 61.4 & 44.4 & 8.4 & 11.5 \\
\hline Brazil & de Oliveira et al. 2009 & 599 & 78.3 & 21.7 & 78.3 & 21.7 & 67.8 & 6.5 & 4.8 \\
\hline Brazil & Ito et al. 2009 & 496 & 67.5 & 32.5 & 77.2 & 22.8 & 54.2 & 7.9 & 13.5 \\
\hline Brazil & Fonseca et al. 2012 & 493 & 50.5 & 49.1 & 74.8 & 25.1 & 85 & 17.7 & 31.4 \\
\hline Italy & Ascani et al. 2006 & 454 & 89.2 & 10.3 & 93.4 & 6.6 & 63.2 & 1.8 & 3.3 \\
\hline Nigeria & Lawal et al. 2013 & 413 & 46.5 & 53.5 & 55 & 45 & 40.9 & 22.5 & 14.8 \\
\hline Mexico & Meija-Velazquez et al. 2012 & 360 & 67 & 23 & 76.4 & 23.6 & 65.6 & 5 & 4.7 \\
\hline Israel & Bello et al. 2012 & 330 & 66.4 & 33.7 & 66.7 & 33.3 & 70.5 & 31.8 & 28.2 \\
\hline Congo & Kayeme et al. 2002 & 275 & 65.5 & 34.5 & 61.5 & 38.5 & 55.3 & 16 & 8 \\
\hline Uganda & Vuhahula 2004 & 268 & 32.8 & 67.2 & 54.1 & 45.9 & 73.8 & 29.3 & 20.3 \\
\hline Jordan & Ma'aita et al. 1999 & 221 & 68.3 & 31.7 & 81 & 19 & 62.9 & 5.4 & 17.2 \\
\hline Tanzania & Masanja et al. 2003 & 133 & 54 & 46 & 42.4 & 57.6 & 44.4 & 24.8 & 9.8 \\
\hline Iran & Ansari et al. 2007 & 130 & 68.5 & 31.5 & 86.1 & 13.9 & 65.4 & 2.3 & 11.5 \\
\hline Brazil & Present study & 109 & 78 & 22 & 74.3 & 25.7 & 63.3 & 12.8 & 4.6 \\
\hline Nigeria & Otoh et al. 2005 & 79 & 55.7 & 44.3 & 58.2 & 41.8 & 44.3 & 8.9 & 10.1 \\
\hline
\end{tabular}

Table 5. Reports of salivary gland tumors in different states and regions in Brazil.

\begin{tabular}{lll}
\hline State/Region & \multicolumn{1}{c}{ Authors } & $\begin{array}{c}\text { Number of cases } \\
\text { (n) }\end{array}$ \\
\hline Goiás/Middle-West & de Oliveira et al. 2009 & 599 \\
Paraná/South & Ito et al. 2009 & 496 \\
$\begin{array}{l}\text { Paraná/South - } \\
\text { São Paulo/Southeast }\end{array}$ & Fonseca et al. 2012 & 493 \\
Rio Grande do Sul/South & Present study & 109 \\
\hline
\end{tabular}

of malignant SGTs. ${ }^{11}$ In such cases, the uncommon findings may be explained by the fact that the studies were conducted at tertiary centers, which receive more severe cases of SGTs.

Pleomorphic adenoma is a benign neoplasm composed of epithelial and myoepithelial cells arranged in a large variety of morphological patterns, with areas of mesenchymal differentiation. In the present series, this tumor was the most frequent type of SGT, accounting for $63.3 \%$ of all tumors and $81.2 \%$ of benign tumors. The majority of such cases $(73.9 \%)$ were located in major salivary glands. The frequency of pleomorphic adenoma ranges from $40.9 \%$ to $73.8 \%$ of all STGs (Table 4). ${ }^{11,21}$ Studies involving large series of SGTs report similar results, with pleomorphic adenoma representing $60 \%$ to $73 \%$ of parotid gland tumors as well as $40 \%$ to $60 \%$ of submandibular and minor salivary gland tumors. ${ }^{11,21}$ All cases of pleomorphic adenoma reported in the present study were treated by surgery and recurrence was observed in four cases (3.66\%).

Adenoid cystic carcinoma was the most prevalent malignant SGT (14 cases), representing $12.8 \%$ of all tumors and $58.3 \%$ of malignant tumors, followed by mucoepidermoid carcinoma and acinic cell carcinoma. The predominance of adenoid cystic carcinoma has been described in studies conducted in Congo, Tanzania, Croatia and Nigeria. In contrast, studies conducted in Iran, Brazil, Jordan, the USA, the United Kingdom and Italy report a greater frequency of mucoepidermoid carcinoma than adenoid cystic carcinoma, whereas similar distribution between these two types of SGTs has been reported in China, Finland and Mexico (Table 4). These findings 
suggest geographic variation in the frequency of malignant SGTs.

Adenoid cystic carcinoma exhibited the worst behavior among all SGTs analyzed. This tumor has a slow growth pattern with the early nerve and lymph node involvement. Advanced tumors require surgery and radiation therapy. ${ }^{25}$ In the present study, adenoid cystic carcinoma recurred in four cases (28.6\%) and death occurred in an additional two cases $(14.28 \%)$. The patients in these cases were in TNM stages III or IV and received surgery plus radiation therapy. According to previous studies, the majority of patients with distant metastasis of an adenoid cystic carcinoma have tumor size of T3 or $\mathrm{T} 4$ and that surgery and radiation therapy achieve excellent results regarding both local and regional control. ${ }^{5,26,27}$ Another important aspect is the presence of perineural invasion, which is a common finding in adenoid cystic carcinoma that appears to contribute to a worse outcome. ${ }^{27}$ The mean follow-up period in the present study was 7.4 years and a high survival was observed. However, previous studies indicate that survival rates are usually high in the first five years, whereas the cure rate over a 20 -year period is much lower. $5,8,26,27$

\section{References}

1. Oliveira FA, Duarte EC, Taveira CT, Maximo AA, Aquino EC, Alencar RC et al. Salivary gland tumor: a review of 599 cases in a Brazilian population. Head Neck Pathol. 2009;3(4):271-5. doi:10.1007/s12105-009-0139-9

2. Mariano FV, Silva SD, Chulan TC, Almeida OP, Kowalski LP. Clinicopathological factors are predictors of distant metastasis from major salivary gland carcinomas. Int J Oral Maxillofac Surg. 2011;40(5):504-9. doi:10.1016/j.ijom.2010.12.002

3. Eveson JW, Cawson RA. Salivary gland tumours: a review of 2410 cases with particular reference to histological types, site, age and sex distribution. J Pathol. 1985;146(1):51-8. doi:10.1002/path.1711460106

4. Terhaard $\mathrm{CH}$, Lubsen $\mathrm{H}$, Van der Tweel I, Hilgers FJ, Eijkenboom WM, Marres HA et al. Salivary gland carcinoma: independent prognostic factors for locoregional control, distant metastases, and overall survival: results of the Dutch head and neck oncology cooperative group. Head Neck. 2004;26(8):681-93. doi:10.1002/hed.10400

5. Guzzo M, Locati LD, Prott FJ, Gatta G, McGurk M, Licitra L. Major and minor salivary gland

\section{Conclusion}

In this retrospective study, major salivary glands were more affected than minor glands by neoplastic processes and pleomorphic adenoma and adenoid cystic carcinoma were the most frequent benign and malignant tumors, respectively, at a tertiary health center in southern Brazil. Analyzing the present findings in light of data from previous studies on SGTs, one may infer that some demographic characteristics (e.g., gender and age) and the predominance of malignant tumors (e.g., adenoid cystic carcinoma and mucoepidermoid carcinoma) vary in different geographic regions. Factors that influence SGT behavior and prognosis should be investigated further.

\section{Acknowledgments}

The authors are grateful to Flavia Rejane Giusti for technical support. This study was supported by the Postgraduate Research Group of the Hospital de Clinicas de Porto Alegre (GPPG/FIPE: 12-0339). Luise Meurer, Lelia Batista de Souza, Pablo Agustin Vargas and Manoela Domingues Martins are research fellows of the Brazilian National Council of Scientific and Technological Development (Conselho Nacional de Desenvolvimento Científico e Tecnológico - CNPq).

tumors. Crit Rev Oncol Hematol. 2010;74(2):134-8. doi:10.1016/j.critrevonc.2009.10.004

6. Ito FA, Ito K, Vargas PA, Almeida OP, Lopes MA. Salivary gland tumors in a Brazilian population: a retrospective study of 496 cases. Int J Oral Maxillofac Surg. 2005;34(5):533-6. doi:10.1016/j.ijom.2005.02.005

7. Fonseca FP, Carvalho MV, Almeida OP, Rangel AL, Takizawa MC, Bueno AG et al. Clinicopathologic analysis of 493 cases of salivary gland tumors in a Southern Brazilian population. Oral Surg Oral Med Oral Pathol Oral Radiol. 2012;114(2):230-9. doi:10.1016/j.oooo.2012.04.008

8. Li LJ, Li Y, Wen YM, Liu H, Zhao HW. Clinical analysis of salivary gland tumor cases in West China in past 50 years. Oral Oncol. 2008;44(2):187-92. doi:10.1016/j.oraloncology.2007.01.016

9. Al-Khateeb TH, Ababneh KT. Salivary tumors in north Jordanians: a descriptive study. Oral Surg Oral Med Oral Pathol Oral Radiol Endod. 2007;103(5):e53-9. doi:10.1016/j.tripleo.2006.11.017 
10. Bello IO, Salo T, Dayan D, Tervahauta E, Almangoush A, Schnaiderman-Shapiro A et al. Epithelial salivary gland tumors in two distant geographical locations, Finland (Helsinki and Oulu) and Israel (Tel Aviv): a 10-year retrospective comparative study of 2,218 cases. Head Neck Pathol. 2012 Jun;6(2):224-31. doi:10.1007/s12105-011-0316-5

11. Lawal AO, Adisa AO, Kolude B, Adeyemi BF, Olajide MA. A review of 413 salivary gland tumours in the head and neck region. J Clin Exp Dent. 2013;5(5):e218-22. doi:10.4317/jced.51143

12. Mejia-Velazquez CP, Duran-Padilla MA, Gomez-Apo E, Quezada-Rivera D, Gaitan-Cepeda LA. Tumors of the salivary gland in Mexicans. A retrospective study of 360 cases. Med Oral Patol Oral Cir Bucal. 2012;17(2):e183-9. doi:10.4317/medoral.17434

13. Spiro RH. Salivary neoplasms: overview of a 35-year experience with 2,807 patients. Head Neck Surg. 1986;8(3):177-84. doi:10.1002/hed.2890080309

14. Bjorndal K, Krogdahl A, Therkildsen MH, Overgaard J, Johansen J, Kristensen CA et al. Salivary gland carcinoma in Denmark 1990-2005: outcome and prognostic factors. Results of the Danish Head and Neck Cancer Group (DAHANCA). Oral Oncol. 2012;48(2):179-85. doi:10.1016/j.oraloncology.2011.09.005

15. Lukšić I1, Virag M, Manojlović S, Macan D. Salivary gland tumours: 25 years of experience from a single institution in Croatia. J Craniomaxillofac Surg. 2012;40(3):e75-81. doi:10.1016/j.jcms.2011.05.002

16. Tian Z, Li L, Wang L, Hu Y, Li J. Salivary gland neoplasms in oral and maxillofacial regions: a 23-year retrospective study of 6982 cases in an eastern Chinese population. Int J Oral Maxillofac Surg. 2010;39(3):235-42. doi:10.1016/j.ijom.2009.10.016

17. Barnes LE, Reichart P, Sidransky D. Patholoy and genetics of head and neck tumors. Lyon: IARC Press; 2005.
18. Kayembe MK, Kalengayi MM. Salivary gland tumours in Congo (Zaire). Odontostomatol Trop. 2002;25(99):19-22.

19. Ansari MH. Salivary gland tumors in an Iranian population: a retrospective study of 130 cases. J Oral Maxillofac Surg. 2007;65(11):2187-94. doi:10.1016/j.joms.2006.11.025

20. Otoh EC, Johnson NW, Olasoji H, Danfillo IS, Adeleke OA. Salivary gland neoplasms in Maiduguri, north-eastern Nigeria. Oral Dis. 2005;11(6):386-91. doi:10.1111/j.1601-0825.2005.01137.x

21. Vuhahula EA. Salivary gland tumors in Uganda: clinical pathological study. Afr Health Sci. 2004;4(1):15-23.

22. Shishegar M, Ashraf MJ, Azarpira N, Khademi B, Hashemi B, Ashrafi A. Salivary gland tumors in maxillofacial region: a retrospective study of 130 cases in a southern Iranian population. Patholog Res Int. 2011;2011:934350. doi:10.4061/2011/934350

23. Jones AV, Craig GT, Speight PM, Franklin CD. The range and demographics of salivary gland tumours diagnosed in a UK population. Oral Oncol. 2008;44(4):407-17. doi:10.1016/j.oraloncology.2007.05.010

24. Ma'aita JK, Al-Kaisi N, Al-Tamimi S, Wraikat A. Salivary gland tumors in Jordan: a retrospective study of 221 patients. Croat Med J. 1999;40(4):539-42.

25. Triantafillidou K, Iordanidis F, Psomaderis K, Kalimeras E. Acinic cell carcinoma of minor salivary glands: a clinical and immunohistochemical study. J Oral Maxillofac Surg. 2010;68(10):2489-96. doi:10.1016/j.joms.2009.09.065

26. Seethala RR. An update on grading of salivary gland carcinomas. Head Neck Pathol. 2009;3(1):69-77. doi:10.1007/s12105-009-0102-9

27. Bhayani MK, Yener M, El-Naggar A, Garden A, Hanna EY, Weber RS et al. Prognosis and risk factors for early-stage adenoid cystic carcinoma of the major salivary glands. Cancer. 2012;118(11):2872-8. doi:10.1002/cncr.26549 